\title{
PRÁTICAS DE INTERVENÇÃO PRECOCE NA INFÂNCIA - AS NECESSIDADES DAS FAMÍLIAS DE CRIANÇAS COM NECESSIDADES EDUCATIVAS ESPECIAIS
}

\author{
Manuela Gonçalves, Cristina Simões1
}

\begin{abstract}
Resumo: A Intervenção Precoce na Infância e a Educação Especial foram caminhando lado a lado no atendimento de crianças com Necessidades Educativas Especiais e suas famílias. Este facto é suportado pelo destaque que o recente Decreto-Lei $n^{\circ} 3 / 2008$, de 7 de Janeiro, atribuiu à Intervenção Precoce na Infância e a legislação específica, que cria o Sistema Nacional de Intervenção Precoce (SNIPI), o Decreto-Lei n 281/2009, de 6 de Outubro.

$\mathrm{O}$ nascimento de uma criança com Necessidades Educativas Especiais (NEE) provoca nas famílias uma série de alterações ao nível das suas necessidades e prioridades. Neste sentido, o nosso estudo assentou fundamentalmente na auscultação das opiniões de famílias para identificar as suas necessidades e percebermos as suas expectativas, face à utilização de um recurso formal ao dispor na comunidade, o jardim-de-infância.

Fizemos um estudo quantitativo do levantamento de necessidades, em famílias que já usufruem de Intervenção Precoce na Infância, numa amostra representativa de 25 famílias, no qual podemos concluir que as necessidades mais comuns são ao nível de acesso a recursos logísticos e técnicos específicos. Sobressaímos o facto de o jardim-deinfância constituir um recurso formal que as famílias inquiridas perspectivam como resposta pedagógica, onde pretendem a inclusão dos seus filhos.
\end{abstract}

Palavras-chave: Intervenção Precoce na Infância, Necessidades Educativas Especiais, Família, Necessidades e Recursos.

${ }^{1}$ Professoras de Educação Especial. E-mail: manuelamonteiro@iol.pt; cristinaferreira@iol.pt 


\begin{abstract}
Early Intervention and Special Eduaction stand side by side, in what concerns the caring of children with special educational needs and their families. The result is the emphasis given by the recent law 3/2008, January 7 , to the Early Intervention, and the own legislation which created the National System of Early Intervention SNIPI, the law 281/2009, October 6.

The birth of a child with special educational needs causes a series of changes, in terms of, the families' needs and priorities.

This way, our study was mainly based on the families' opinion in identifying their needs and also in understanding their expectactions towards the use of a formal resource, which is available in the community - the Kindergarten.

We reflected on the quantitative needs assessment of 25 inquired families, who already benefit of Early Intervention, and we concluded that their more common needs are felt at the level of access to logistical resources and specialized tecnicians.

As Early Intervention tecnicians we could also conclude that Kindergarten is a formal resource that the inquired families prospect as a pedagogical response, where they want their childrens' integration.
\end{abstract}

Keywords: Early Intervention; Special Educational Needs; Family; Needs and Resources

\title{
Introdução
}

À família é reconhecido um papel fundamental e determinante para o desenvolvimento harmonioso da criança (Sousa, 1998; Seraceno, 1998; Relvas, 2000; Serrano, 2007). Esta é considerada um grupo social primário que desempenha uma função formativa e determinativa no desenvolvimento cognitivo e afectivo da criança, bem como na satisfação das necessidades mais básicas e diárias, tais como a alimentação, a saúde e o vestuário (Pereira, 1998; Sampaio e Gameiro, 1998). Influencia ainda, o modo como a criança se situa e interage na sociedade, mesmo em idade adulta.

É no seio da família que a criança vai adquirir toda uma herança cultural, com valores próprios que irão influenciá-la pela vida fora. Isto significa que se promovam actividades em contextos diferentes e variados, na comunidade onde a criança e a família estão inseridas (Pimentel, 1997; Sousa, 1998; Leitão, 2004; Serrano, 2007). Desta forma, será através da identificação com os pais e demais membros da família, bem como as reacções destes ao seu comportamento, que a criança tem o seu primeiro contacto com o mundo. Inserida nos seus contextos naturais da comunidade, aprendem a desenvolver os papéis e atitudes essenciais para o seu processo de socialização (Vieira, 1992; Relvas, 1996; Pimentel, 1997; Brazelton e Cramer, 1989; Sousa, 1998; Seraceno, 1998; Leitão, 2004, Serrano, 
2007). Posteriormente, esse papel caberá também ao jardim-de-infância, o qual é responsável pela importante tarefa de inclusão, promovendo a consciencialização e a sensibilização dos membros da comunidade local. Por seu lado, ao jardim-deinfância compete assegurar de forma inclusiva as respostas adequadas ao desenvolvimento de todas as crianças, designadamente nas áreas de comunicação, socialização, cognição e na área emocional (Ministério da Educação, 1997). Os espaços devem ser organizados para que se possibilite a envolvência activa, criem oportunidades de experiências de aprendizagem que estimulem o desenvolvimento global de todas as crianças, promovendo-se a autonomia, não se esquecendo a individualidade e as características de cada criança (Ministério da Educação, 1997; Serrano, 2007).

Sabendo que é na família que as primeiras interacções se estabelecem continuadamente, as relações familiares são uma componente essencial no ambiente de crescimento e desenvolvimento da criança (Pimentel, 1997; Sousa, 1998; Correia e Serrano, 2000; Relvas, 2000; Leitão, 2004). Sendo este um processo dinâmico e recíproco, o foco da intervenção deve contemplar toda a família, pois ela constitui um sistema transaccional, dentro do próprio sistema (Bronfenbrenner, 1974, citado por Portugal, 1992).

Segundo Brazelton e Cramer (1989) e Pimentel (1997), a interacção tem impacto quer na família quer na criança, na medida em que, os técnicos de Intervenção Precoce na Infância (IPI) têm de valorizar o trabalho e a cooperação com esta entidade tão valiosa para a criança, pois as famílias têm competências.

Quando nasce um filho com Necessidades Educativas Especiais (NEE), com características distintas do padrão normal implica, para a família, além da decepção inicial, um conjunto de situações críticas, geralmente acompanhadas de sentimentos e emoções dolorosas (Serrano e Correia, 2005). Neste processo, as famílias passam por diversas fases cíclicas, incluindo o choque inicial da descoberta, a negação do diagnóstico e busca por curas milagrosas, o luto e a depressão, até que possam entrar no estágio de aceitação e adaptação (Correia e Serrano, 2000; Serrano, 2007).

É nesta procura de alternativas que, por vezes, as famílias chegam às Equipas Locais de Intervenção (ELI), designação introduzida pelo actual Decreto-Lei $n^{\circ}$ 281/2009, de 6 de Outubro, geralmente encaminhados pelo sector da saúde, sentindo necessidade de serem apoiadas e ouvidas.

Podemos então definir IPI, como a prestação de serviços educativos, terapêuticos e sociais, com o objectivo de minimizar efeitos nefastos ao desenvolvimento de crianças com NEE (Correia e Serrano, 2000). Por outro lado, McWilliam et al. (2003) referem que a IPI pode iniciar-se entre o nascimento e a idade escolar, sendo várias as vantagens em começar o mais cedo possível.

Conclui-se que a IPI deve optimizar as condições da interacção criança/família, mediante a informação sobre a problemática em causa, o reforço das respectivas capacidades e competências das famílias, designadamente na 
identificação e utilização de redes de apoio social da comunidade (Correia, 1999; Correia e Serrano, 2000; Bairrão e Almeida, 2003; McWilliam et al., 2003; Serrano, 2007; Alves, 2009; Decreto-Lei no 281/2009, de 6 de Outubro).

Estes princípios remetem-nos para uma intervenção de práticas centradas na família, constituindo o eixo nuclear da actuação. O reconhecimento de que todas as famílias têm capacidades e pontos fortes tornou-se no legado mais importante das práticas de IPI. A elas pertence-lhe a condução e a tomada de decisões uma vez que reconhecem como apropriado o apoio de elementos externos nas suas vidas (Tavares e Alarcão, 1999; Cruz et al., 2003; McWilliam et al., 2003).

Por sua vez, o técnico responsável de caso que representa toda a equipa de IPI deve respeitar os direitos das famílias e as suas preferências (Cruz et al., 2003; McWilliam et al., 2003; Serrano 2007). Nesta relação, é importante criar uma atmosfera em que ambas as partes se sintam livres e responsáveis, trabalhando com o mesmo objectivo, ou seja, para o mesmo fim (Correia e Serrano, 2000; Ruivo e Almeida, 2002; McWilliam et al., 2003). O técnico deve actuar consoante as necessidades específicas e particulares de cada família, respeitando a sua individualidade, os seus valores e as suas crenças (Correia e Serrano, 2000; Ruivo e Almeida, 2002; McWilliam et al., 2003). Nesta linha de pensamento, deve ser um bom ouvinte, criar e expressar empatia, mostrar disponibilidade, deixar que seja a família a tomar as decisões e que conduza a intervenção (Almeida, 2000; Ruivo e Almeida, 2002; Cruz et al., 2003; McWilliam et al., 2003).

Nesta relação, construída com base numa parceria de amizade e de colaboração, que respeita os valores, crenças e ideologias familiares, o técnico poderá ser visto como mais um elemento familiar (McWilliam et al., 2003). Deste modo, parece-nos mais correcto que, em vez de falarmos sobre participação da família nos serviços de IPI, começarmos a falar da participação do técnico nas metas e objectivos das famílias.

As práticas de intervenção centradas na família devem incluir a identificação das necessidades da mesma, o estabelecimento de objectivos e prioridades, a selecção dos serviços, ou seja, os recursos formais e informais necessários para encontrar respostas (McWilliam et al., 2003). Não devemos esquecer que as práticas centradas na família reflectem uma visão mais realista e positiva das famílias, reconhecendo as suas necessidades, como também os pontos fortes para as ultrapassarem (Coutinho, 1996; Pimentel, 1997; Pereira, 1998; Morgado e Beja, 2000; McWilliam et al., 2003; Serrano, 2007). A complexidade dos problemas e o facto dos pais e técnicos valorizarem o papel da família baseia-se na premissa de que uma vida familiar de sucesso requer que todas as necessidades, incluindo as dos pais, sejam identificadas e resolvidas (Serrano, 2007). Lembramos que só respondendo às necessidades dos pais é que os técnicos poderão responder às necessidades dos filhos (Sousa, 1998). 
Podemos então constatar, que o nascimento de uma criança com NEE pressupõe uma série de alterações ao nível das necessidades e dinâmicas familiares. Tendo em conta que a adequação do comportamento dos pais a um filho com NEE é, muitas vezes, um processo longo e penoso, em que é importante poderem contar com a colaboração e ajuda actuante de serviços ao dispor na comunidade. Partindo deste pressuposto e porque somos confrontados diariamente com esta realidade, importa conhecer as práticas que estão a ser usadas junto das mesmas.

Segundo Coutinho (1996), Pimentel (1997), Pereira (1998), Correia e Serrano (2000), Morgado e Beja (2000), Ruivo e Almeida (2002), Cruz et al. (2003), McWilliam et al. (2003), Serrano (2007) e Alves (2009), existem benefícios da actuação centrada nas famílias, reconhecendo as necessidades de cada membro familiar e não apenas da criança com NEE.

Assim, a actuação centrada na família requer uma rede de apoio social forte e coesa, com recursos formais e informais, de forma a assegurar que a intervenção está a ser benéfica, permitindo ajudar a família a tornar-se mais funcional e independente, criando-se oportunidades para aplicar as suas competências (Ruivo e Almeida, 2002; Cruz et al., 2003; McWilliam et al., 2003; Serrano, 2007).

Tendo em conta estes pressupostos surgiu a necessidade de responder à seguinte questão de partida: quais são as necessidades e prioridades sentidas pelas famílias face ao nascimento de uma criança com Necessidades Educativas Especiais?

\section{2 - Objectivos do Estudo}

A finalidade ou o objectivo geral deste estudo consiste em conhecer as necessidades e prioridades designadas pelas famílias face ao nascimento ou posterior diagnóstico de uma criança com NEE e ainda perceber se o jardim-deinfância será, na expectativa familiar, um bom recurso formal ao dispor na comunidade, encarando-o como resposta possível à hierarquia das suas necessidades.

Pretendemos especificamente:

- Conhecer a concepção do trabalho em IPI, fundamentado em práticas de actuação centradas na família;

- Identificar as necessidades das famílias de crianças com NEE;

- Verificar, na opinião das famílias, qual a importância da inclusão das suas crianças no jardim-de-infância. 


\section{3 - Procedimentos Metodológicos}

O tipo de investigação escolhido, para este estudo, foi a investigação quantitativa que, segundo Freixo (2009), constitui um processo sistemático de recolha de dados observáveis e quantificáveis. A investigação é descritiva, procurando-se criar relações entre os vários elementos e dados recolhidos, em ordem à compreensão dos mesmos; identificar as práticas que prevalecem; as crenças, pontos de vista ou atitudes considerados; processos em decurso e efeitos sentidos ou tendências em desenvolvimento (Carmo e Ferreira, 1998).

Elaborámos, como instrumento de recolha de informação, um questionário específico para este estudo. A utilização do inquérito por questionário fundamenta-se pelo facto de ser considerado o mais adequado, na medida em que, "se presta bem a uma utilização pedagógica pelo carácter muito preciso e formal da sua construção e da sua aplicação" (Quivy, 1998, p.187). Segundo Tuckman (1994), os questionários são processos para adquirir dados acerca das pessoas.

Num primeiro momento seleccionamos o grupo de sujeitos e contactamos, telefonicamente, as Equipas Coordenadoras da IPI que servem a área geográfica que seleccionamos para a nossa amostra. Escolhemos para o estudo, 5 concelhos do Distrito de Viseu.

$\mathrm{O}$ passo seguinte foi o contacto pessoal com elementos pertencentes às Equipas de Intervenção Local, com a finalidade de solicitar a sua colaboração na distribuição dos questionários pelas famílias e a indicação de que, quando necessário, estas poderiam ajudá-las no seu preenchimento. A nossa amostra é assim constituída por um total de 25 famílias, pertencentes a 5 concelhos do distrito de Viseu. Deste modo, é uma amostra não probabilística por conveniência. Escolhemos como população ou universo estatístico, famílias de crianças com NEE com idades entre os 0 aos 5 anos de idade. Foram entregues e recolhidos 25 questionários, devidamente preenchidos.

\section{4 - Apresentação dos Resultados}

O nosso estudo empírico é um modelo de prática em Intervenção Precoce na Infância, que se pretende ser centrado na família. Partimos dos sentimentos que as famílias da nossa amostra revelam face ao nascimento de uma criança com NEE e efectuamos uma escala de necessidades familiares. Auscultamos ainda as mesmas face à sua expectativa na utilização do jardim-de-infância como um recurso social, para dar resposta a essas necessidades. Por outro lado, procuramos perceber se este constitui um recurso formal ao dispor na comunidade. 
Figura $\mathrm{n}^{\circ} 1$ - Sentimento das famílias ao receberem a notícia de uma criança com

NEE.

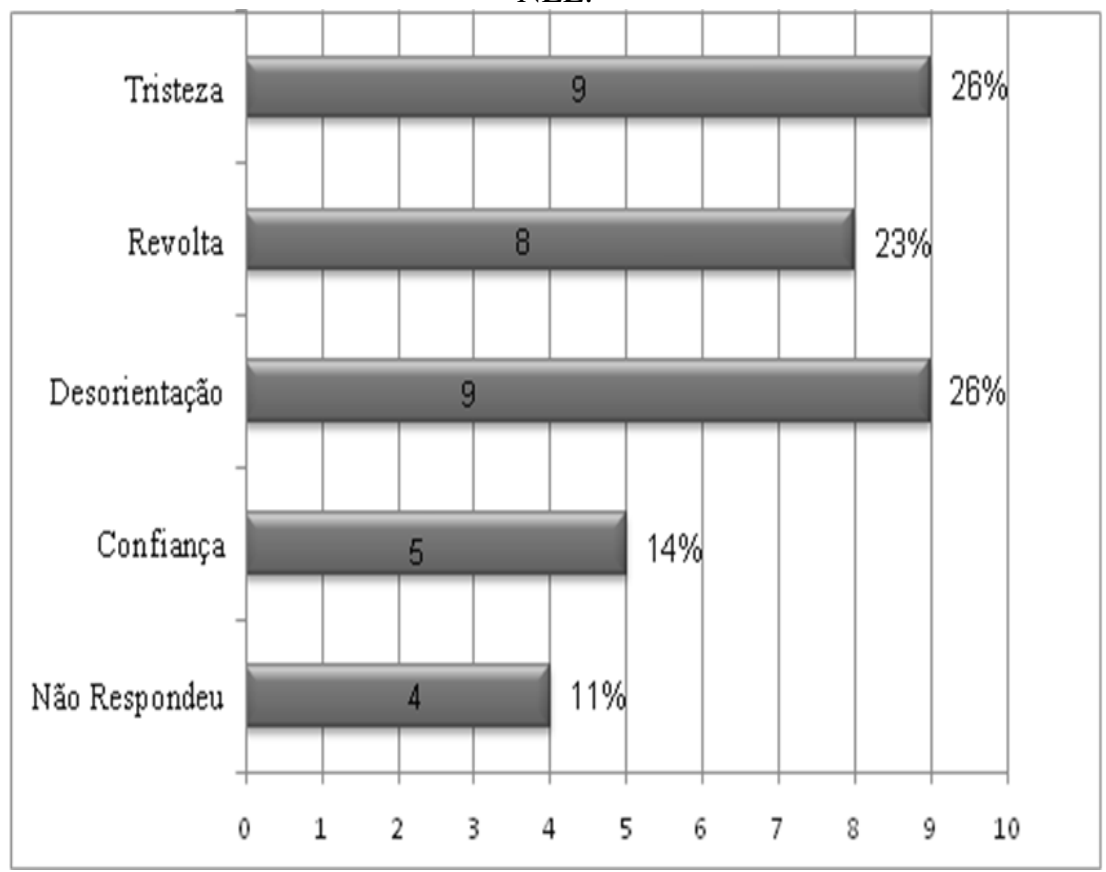

Relativamente ao sentimento, após a notícia das necessidades específicas da criança, verificamos que os sentimentos variam, em percentagens, entre a tristeza com $26 \%$ de respostas e desorientação com $26 \%$, a revolta com $23 \%$, a confiança com $14 \%$ e não responderam a esta questão $11 \%$ dos inquiridos.

Figura nº 2 - Práticas de actuação centradas na família.

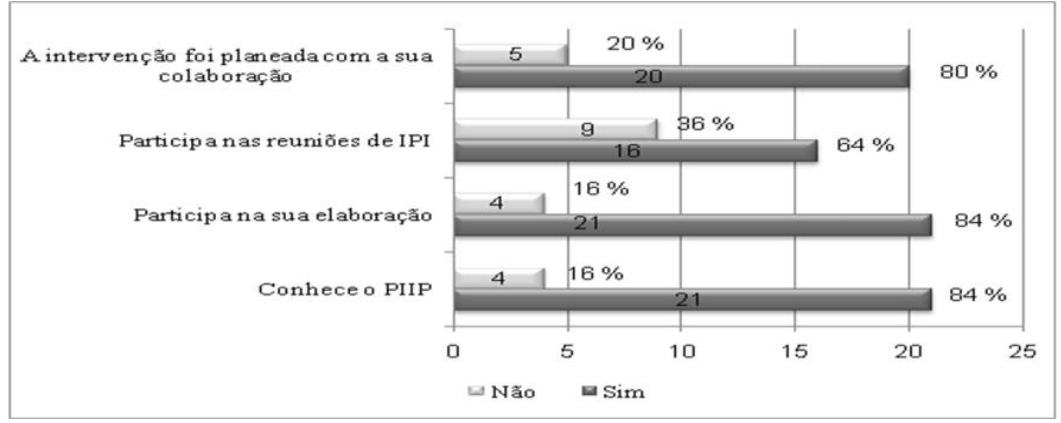


Os dados referentes à figura $\mathrm{n}^{\mathrm{0}} 2$ mostram-nos as práticas que são efectuadas pelos serviços de IPI. Quando se pergunta se a intervenção foi planeada com a colaboração da família, $80 \%$ respondem que sim e apenas $20 \%$ referem que não.

Quanto aos itens de participação nas reuniões de IPI, 64\% referem que participam nas reuniões conjuntamente com os técnicos, $36 \%$ referem não participar nas mesmas. As famílias, da presente amostra, referiram que conhecem e participam na elaboração do Plano Individual de Intervenção Precoce (PIIP), $84 \%$, enquanto $16 \%$ das famílias responderam não ter participado neste processo. As famílias não justificam esta resposta.

Organizamos uma escala de necessidades direccionada a obter informação sobre as necessidades familiares actuais (Cf. Figura ${ }^{\circ} 3$ ).

Figura $\mathrm{n}^{\mathrm{o}} 3$ - Escala de necessidades familiares.

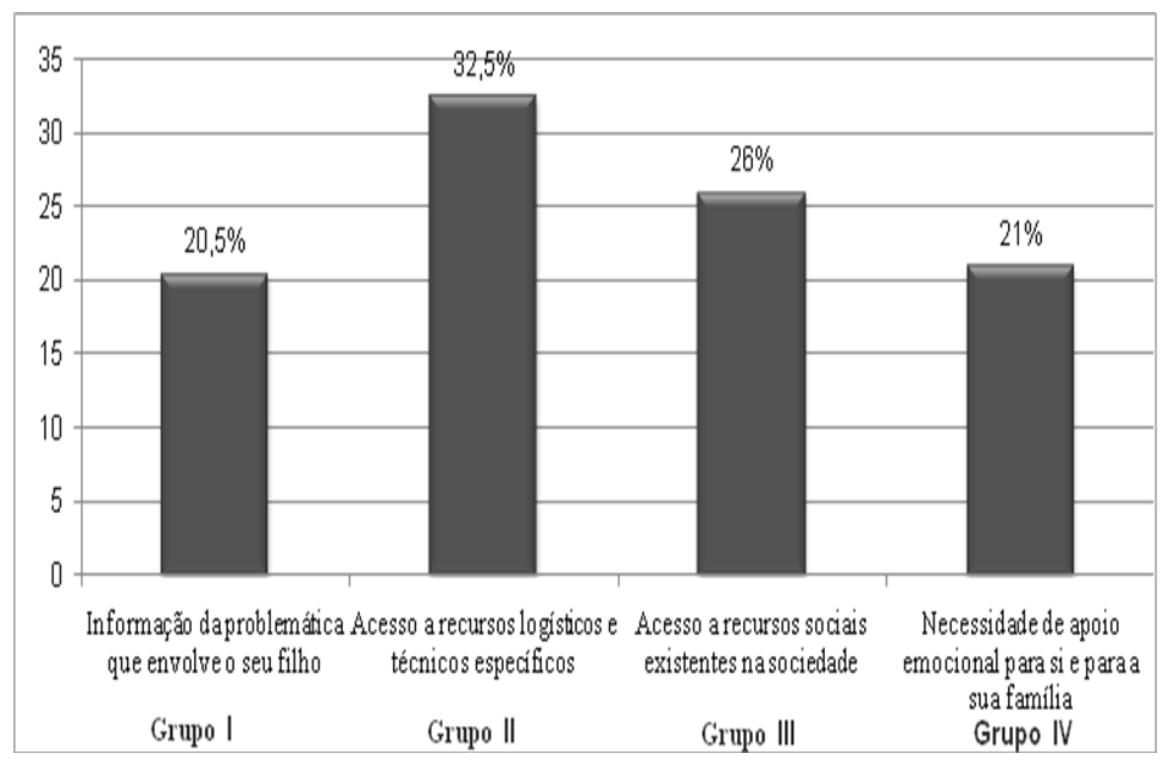

Relativamente à figura $\mathrm{n}^{\circ}$ 3, os dados indicam-nos que 32,5\% das famílias da nossa amostra têm necessidades de informação para obter acesso a recursos logísticos e técnicos específicos e $26 \%$ precisam de ter acesso a recursos sociais existentes. A necessidade de apoio para a família representa $21 \%$ e ainda a informação acerca da problemática que envolve a criança é referida por $20,5 \%$ das famílias analisadas. 
Figura no 4 - A importância da entrada da criança no jardim-de-infância.

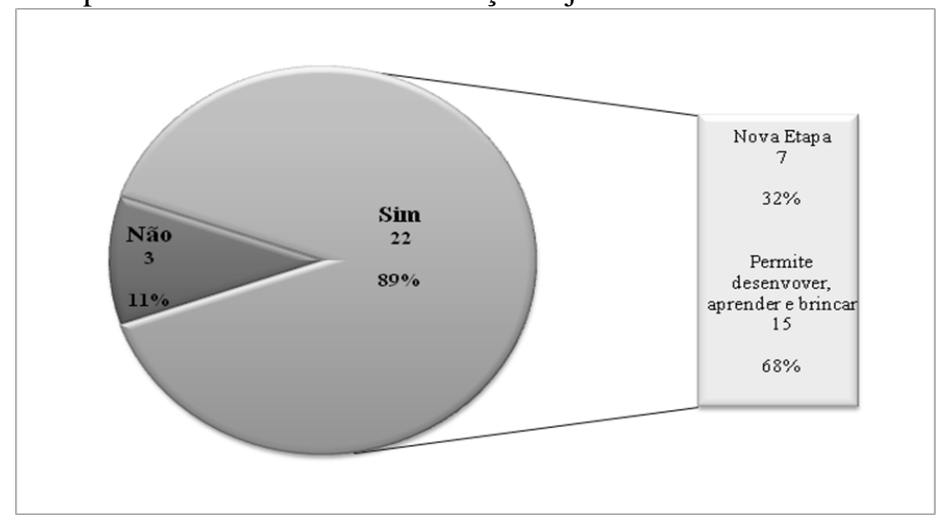

Como podemos analisar através da observação da figura $\mathrm{n}^{\circ} 4$, obtivemos uma percentagem de $89 \%$ das famílias que referem que é importante que a criança entre no jardim-de-infância e 11\% referem não ser relevante. Quando se pergunta porquê, $68 \%$ dos inquiridos fundamentam que o mesmo irá permitir desenvolver, aprender e brincar. Os restantes $32 \%$ referem ser uma nova etapa na vida da criança e da família.

Figura $\mathrm{n}^{\circ} 5$ - As necessidades específicas das crianças constituíram um obstáculo à inclusão.

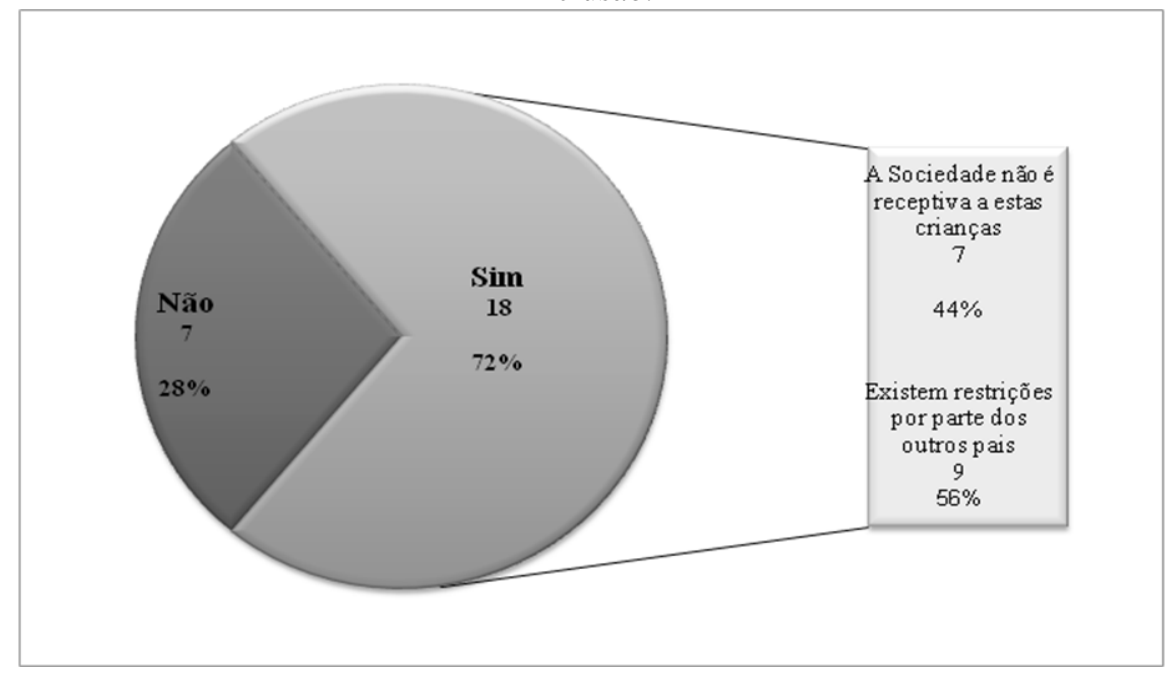


Podemos observar na figura $\mathrm{n}^{\circ} 5$ que a maioria das famílias considera que as necessidades específicas da criança constituem um obstáculo à inclusão escolar (72\%), enquanto $28 \%$ referem que não é um obstáculo. Quando se pergunta porquê, $56 \%$ dizem que ainda existem restrições por parte dos outros pais e $44 \%$ indicam que a sociedade ainda não está receptiva a estas crianças.

Figura $\mathrm{n}^{\circ} 6$ - Conhecer a necessidade da família face à resposta educativa por parte do jardim-de-infância.

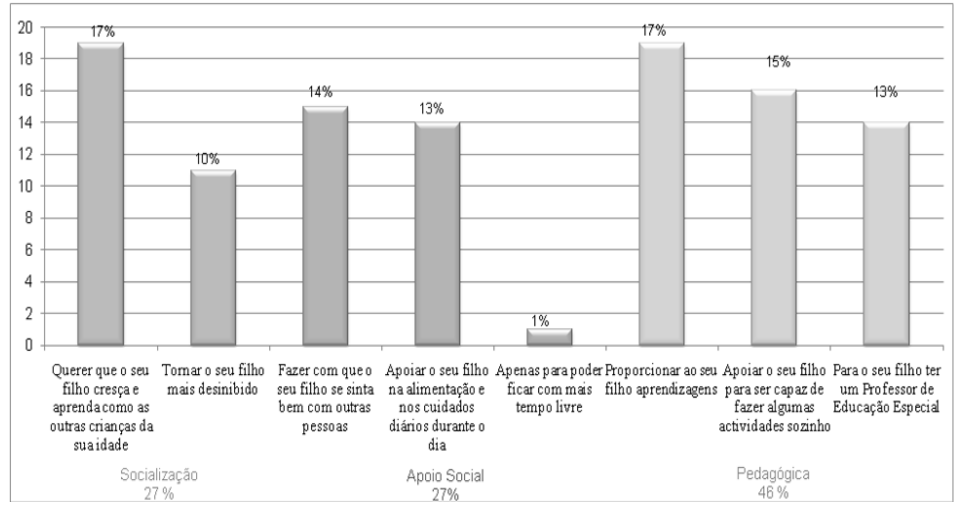

Verificamos, através da figura $\mathrm{n}^{\circ} 6$, que o apoio pedagógico aparece como o mais significativo, $46 \%$, o apoio social com $27 \%$ e o de socialização também com uma percentagem de $27 \%$. Verificamos ainda, pela análise individual de cada item, que a categoria proporcionar aprendizagens e o querer a criança junto dos outros obteve uma percentagem de $17 \%$.

Apoiar o filho a realizar actividades sozinho, $15 \%$; o fazer com que a criança se sinta bem com outras pessoas, $14 \%$; com uma percentagem $13 \%$ temos o apoio à criança na alimentação e nos cuidados diários durante o dia; e com igual percentagem surge a necessidade da criança ter um Professor de Educação Especial. O item tornar o seu filho mais desinibido teve uma percentagem de $10 \%$ e o de ficar com mais tempo livre $1 \%$.

\section{5 - Discussão dos Resultados}

Analisando os dados da nossa investigação, aplicada a um grupo de famílias que estão a ser intervencionadas pelos serviços locais de IPI, podemos concluir que as mesmas têm necessidades de vários níveis, mas também muitas competências e pontos fortes, encarando as dificuldades numa perspectiva direccionada para o futuro. Tiveram conhecimento das NEE precocemente e, na sua maioria, foram informadas por elementos ligados à saúde. Deste modo, 
procuraram outras informações relacionadas com a problemática das crianças, o que vai ao encontro da perspectiva de Pimentel (1997), Pereira (1998), Relvas (2000), Correia e Serrano (2000), Serrano e Correia (2005), Miranda (2002), McWilliam et al. (2003) e Leitão (2004). Sustentados nos mesmos autores, podemos referir que encontramos sentimentos semelhantes face ao nascimento ou à identificação de uma criança com NEE.

Verificamos a tristeza, desorientação e revolta, entendendo o estado emocional dos que não responderam como uma dualidade e ambivalência de sentimentos. É ainda de referir que Pimentel (1997), Pereira (1998), Relvas (2000), Correia e Serrano (2000), Miranda (2002), McWilliam et al. (2003), Leitão (2004) e Serrano e Correia (2005), referem que as famílias passam por um ciclo de sentimentos até que possam entrar na fase de aceitação. No entanto, na presente amostra, observamos a confiança como um dos primeiros sentimentos, pelo que transcrevemos uma mãe que refere "até fiquei feliz, pois pensei que o problema fosse pior".

$\mathrm{Na}$ análise das práticas de actuação centradas nas famílias, fundamentadas por Pereira (1996), Sousa (1998), McWilliam et al. (2003), Bairrão (2004), Serrano (2007) e Alves (2009), o nosso estudo indica-nos que a intervenção foi planeada com a colaboração das mesmas, tendo participado no planeamento da intervenção e daí conhecerem o Plano Individualizado de Intervenção Precoce na Infância. Embora com uma percentagem inferior, ainda existem famílias que não participam nas reuniões com os técnicos de IPI. Parece-nos que podemos concluir que, tanto os técnicos, como as famílias da nossa amostra, conhecem a intervenção e projectam-na de forma colaborativa e em parceria. Autores como Veiga (1995), Almeida (1997), Correia e Serrano (2000), Almeida (2000), Ruivo e Almeida (2002), Cruz et al. (2003), McWilliam et al. (2003), Serrano (2007) e Alves (2009), reconhecem à família um papel fundamental de condução da intervenção, referem as metas para as práticas de intervenção centrada na mesma, consistindo em práticas de actuação capazes de dar poder e capacitar, o que significa criar oportunidades para a família adquirir competência e reforçar o seu funcionamento familiar. Poderemos ainda referir que a família é o elemento mais significativo e importante para a criança, conforme referido por Sousa (1998), Pereira (1998), Correia e Serrano (2000) e Cruz et al. (2003), daí que ninguém saberá fazer as coisas melhor pelos seus filhos do que elas próprias. Por outro lado, para que os pais assumam um papel activo na educação dos seus filhos e no processo de intervenção que lhe é dirigida, o benefício vai-se repercutir em toda a dinâmica familiar, sendo extensível a todos os elementos (Portugal, 1992; Pimentel, 1997; Relvas, 2000).

Como já referimos, após o nascimento ou a identificação de uma criança com NEE, as famílias vêem as suas necessidades e prioridades alteradas (Coutinho, 1996; Pereira, 1998; Morgado e Beja, 2000). O nosso estudo demonstrou que, após o estado de aceitação das NEE, as maiores necessidades e prioridades 
familiares são de vários níveis, entre as quais salientamos: obter informação acerca da problemática que envolve a criança, recorrer a apoio logístico e técnico, aceder a recursos sociais existentes na comunidade, apoio familiar e emocional para si ou para a sua família.

Podemos então concluir que, após o diagnóstico de uma criança com NEE, as famílias sentem necessidades de várias ordens, nomeadamente, ao nível de acesso a recursos logísticos e de técnicos específicos, o acesso a recursos sociais existentes na comunidade, a informação relacionada com a problemática da criança e o apoio familiar e emocional.

Constatamos assim que temos itens que correspondem a necessidades familiares com percentagens elevadas, as quais poderíamos agrupar segundo uma hierarquia, estas iriam emergindo à medida que a do cume fosse obtendo resposta, uma outra, iria emergir e aparecer como prioritária e assim sucessivamente. Tal como nos diz Pereira (1998), Correia e Serrano (2000), McWilliam et al. (2003) e Serrano (2007), para além das necessidades gerais encontradas e identificadas, existem as mais específicas, prevalecendo a mais elevada, desde que as inferiores estejam minimamente satisfeitas. As necessidades familiares minimamente satisfeitas vão influenciar positivamente o comportamento dos elementos familiares e consequentemente o da criança (Morgado e Beja, 2000). Neste sentido, parece-nos que estas necessidades identificadas devem ser exploradas como pistas futuras de actuação da IPI.

Quando sustentamos práticas de intervenção focadas na família importa, após a definição das necessidades e prioridades familiares, encontrar respostas, mantendo estreita colaboração e deixando que as famílias conduzam a acção e tomem as suas decisões.

No nosso estudo, procuramos recursos de apoio formais, existentes na comunidade, que consistissem numa forma de dar resposta às necessidades familiares, designadamente o jardim-de-infância. Tendo em conta que a escala aplicada na nossa amostra, o grupo II da figura $\mathrm{n}^{\mathrm{o}} 3$, ou seja, na categoria de acesso a recursos logísticos e técnicos específicos, foi a que obteve maior percentagem, olhar para o jardim-de-infância como uma possível resposta às necessidades familiares mais comuns, faz todo o sentido. Justificamos esta opinião na medida em que poderá oferecer uma resposta educativa fundamental, com recursos humanos adequados e de fácil acesso a todas as famílias.

Salientamos a elevada percentagem das famílias que consideram importante a entrada das crianças nesta instituição. Quando questionadas porquê, referem que esta é uma nova etapa na vida das crianças e com consequências na família, afirmando ainda que este percurso irá permitir o desenvolvimento, a aprendizagem e a brincadeira. Alguns inquiridos vão ainda mais longe ao referirem que "arranjam amigos da mesma idade".

Salientamos a opinião de Morato (1995), Vieira e Pereira (1996), Correia (1997), Fonseca (1998), Rodrigues (2001), Correia (2003) e DGIDC (2008), que 
entendem as NEE das crianças, não como uma dificuldade particular, mas como um conjunto de características específicas, traduzidas em muitos pontos fortes. Assim, verifica-se a existência de uma NEE quando existe um perfil de funcionalidade com limitações ao nível da actividade e participação, num ou em vários domínios de vida, concomitantes com alterações nas funções e/ou estruturas do corpo, na qual o contexto pode constituir um facilitador ou uma barreira (DGIDC, 2008). Quando tal acontece, e tendo em conta o proclamado na Declaração de Salamanca (Unesco 1994), de uma escola para todos, esta deve mobilizar serviços e valorizar a intervenção especializada e individualizada de forma a promover um desenvolvimento global, envolvendo a família e a comunidade. Sendo assim, a escola inclusiva é aquela que dá resposta às necessidades de todos os alunos, sejam quais forem as suas características, nas escolas do ensino regular da sua comunidade. É esta a escola de qualidade em que acreditamos.

A maioria das famílias inquiridas considera que as NEE da criança constituem um obstáculo para a inclusão escolar. Quando perguntamos porquê, salientam factores relacionados com a sociedade em geral e relacionados com os outros pais, citando "porque as pessoas não gostam de ver meninos diferentes nas escolas com os outros" ou ainda "a sociedade não está pronta para aceitar as diferenças".

Podemos constatar que, apesar das famílias da nossa amostra considerarem o factor inclusão importante e de quererem que os seus filhos frequentem o jardimde-infância com as outras crianças, sentem que ainda existem muitas restrições quer por parte da sociedade, quer por parte dos pais das outras crianças. É de salientar o facto da faixa etária das crianças que representam a nossa amostra familiar ser ao nível da transição da instituição familiar para a escolar. Atendendo que o jardim-de-infância será uma continuação da educação familiar, considerada uma etapa com muitas expectativas, esta deve ser planeada em estreita colaboração com a família (Ministério da Educação, 1997; Serrano e Correia, 2005a). Sublinhamos ainda Portugal (1992), Pimentel (1997), Almeida (2000a), Correia e Serrano (2000) e Serrano (2007), que referem na teoria do desenvolvimento humano a importância das interacções da criança com a família mais chegada, depois com a mais alargada e em seguida com a comunidade que a envolve. Nesta nova etapa escolar, na qual se deve promover a inclusão, é essencial a colaboração activa dos pais/família, devendo a estes caber todas as decisões que devem ser respeitadas pelo técnico de IPI.

No nosso questionário procuramos também saber as expectativas das famílias face ao jardim-de-infância e de que forma este iria dar resposta às suas necessidades e prioridade imediatas. Concluímos que estas desejam uma resposta ao nível pedagógico, sendo este o factor mais relevante. Também referem a socialização e apoio social como factores decisivos. 
Nesta linha de pensamento, devemos reflectir sobre a resposta que o jardimde-infância deve oferecer às crianças com NEE. Carvalho (1996), Miranda (2002) e Serrano e Correia (2005a), salientam que as crianças com NEE têm direito a uma educação de qualidade onde possam obter respostas para as suas necessidades, socializar-se com as outras crianças, aprender junto com elas e conviver com a comunidade educativa da qual fazem parte. Poderíamos partir para outros estudos no sentido de observar como é efectuada a inclusão da criança com NEE no jardim-de-infância, ou ainda saber de que forma os Educadores titulares de grupo oferecem a resposta pedagógica às mesmas.

Tendo em conta que o espaço do jardim-de-infância deve oferecer uma resposta educativa de qualidade fundamentada pelos direitos de igualdade e de inclusão escolar, a nossa amostra demonstrou que as famílias entendem-no na sua maioria como uma questão de socialização e uma questão pedagógica. No entanto, as suas prioridades e necessidades imediatas, como constatámos anteriormente, dão supremacia à resposta pedagógica.

Deste modo, podemos concluir que as metas para as práticas de avaliação e intervenção centradas na família consistem na identificação das suas necessidades e prioridades, na localização de recursos e apoios para as famílias irem ao encontro das respostas às suas necessidades específicas. Por seu lado, o técnico de IPI deve ajudar e colaborar, para que as famílias maximizem as suas capacidades e competências para essa mobilização de recursos. Deste modo, o objectivo da intervenção deve ser o fortalecimento do funcionamento familiar de modo a que as famílias usem os próprios recursos para responderem às necessidades de todos os elementos familiares. Este é o caminho a seguir para potenciarmos famílias ainda mais competentes e independentes dos serviços de apoio, nomeadamente do técnico de IPI que as acompanha.

\section{Conclusão}

Após o nascimento ou o diagnóstico de uma criança com NEE, as famílias passam por muitos ciclos e enfrentam muitas dificuldades, mas lutam... procuram recursos para darem resposta às suas necessidades e prioridades.

$\mathrm{Na}$ hierarquia de necessidades observamos como principal preocupação o acesso a recursos logísticos e técnicos específicos, seguindo-se o acesso a recursos sociais existentes na comunidade. Em terceiro lugar, referem a necessidade de apoio emocional para si e para a sua família e por fim a informação da problemática que envolve a criança. $\mathrm{O}$ que nos faz concluir que as mesmas encaram as dificuldades que sentem numa vertente direccionada para o futuro, de busca e procura de soluções para uma resposta à satisfação das suas necessidades familiares. Tendo em conta que as necessidades satisfeitas, num determinado momento, dão lugar a outras na hierarquia, importa capacitá-las para que as mesmas se sintam seguras e confiantes na resolução dos seus 
próprios obstáculos. Considerando que todas as famílias são únicas e com valores próprios, importa encorajar, colaborar e incentivar, no sentido de que as mesmas o possam fazer por elas e para elas, partindo do princípio que o resultado se vai repercutir na satisfação familiar, influenciando cada e todos os elementos. Assim se justifica uma actuação que evolui ao longo dos tempos, deixando de estar centrada na criança, para se reconhecer a família como o eixo nuclear de actuação. À família se pede colaboração, de forma a se trabalhar com e para o mesmo fim, deixando que a mesma conduza a actuação e definindo ela própria os seus objectivos, que pretendem para si e para os seus elementos familiares.

Após a identificação das necessidades, procurámos um recurso de apoio para dar resposta, neste caso o jardim-de-infância. As famílias, consideram importante a entrada da criança com NEE no jardim-de-infância, para aprenderem a realizar actividades sozinhas e a brincar com as outras crianças. No entanto, consideram que ainda existem muitos obstáculos à inclusão, salientando factores relacionados com a sociedade em geral e com os outros pais em particular.

Salienta-se que as crianças com NEE têm direito a uma educação no âmbito do jardim-de-infância de qualidade, onde possam obter respostas para as suas necessidades contempladas no seu perfil de funcionalidade. Devem socializar com as outras crianças, aprender junto com elas e conviver com a comunidade educativa da qual fazem parte. O jardim-de-infância deve oferecer essa resposta fundamentada pelos direitos de igualdade e de inclusão escolar, constituindo um bom recurso para a satisfação das necessidades imediatas.

Contudo, consideramos que ainda há muita coisa a fazer para que, na altura da transição entre família e jardim-de-infância, o processo se faça com muita tranquilidade, colaboração e interesse da família.

As famílias com crianças NEE contornam muitos obstáculos, por vezes difíceis de ultrapassar, nunca desistindo porque têm muitas competências e poder para os enfrentar.

Consideramos todas e cada uma em particular umas vitoriosas e eternas lutadoras... 


\section{Bibliografia}

ALMEIDA, I. (1997). A Perspectiva Ecológica em Intervenção Precoce. In Revista Cadernos CEAF, 13 (14), 29-40.

ALMEIDA, I. (2000). Evolução das Teorias e Modelos de Intervenção Precoce. Caracterização de uma Prática de Qualidade. In Revista Cadernos CEAF, 15(16), 29-46.

ALMEIDA, I. (2000a). A importância da Intervenção Precoce no Actual Contexto Sócio Educativo. In Revista Cadernos CEAF, 15 (16), 55-74.

ALVES, M. (2009). Intervenção Precoce e Educação Especial. Práticas de Intervenção Centradas na Família. Viseu: Psicosoma.

BAIRRÃO, J. e Almeida, I. (2003). Questões Actuais em Intervenção Precoce. In J. Bairrão e I. Almeida, Psicologia, vol. XVII (pp. 15-29). Porto: Faculdade de Psicologia e de Educação da Universidade do Porto.

BRAZELTON, T. e Cramer, B. (1989). A Relação mais Precoce, os Pais, os Bebés e a Interacção Precoce. Lisboa: Terramar.

CARMO, H. e Ferreira, M. (1998). Metodologia da Investigação. Guia para a Auto-Aprendizagem. Lisboa: Universidade Aberta.

CARVALHO, I. (1996). Currículo no Pré-Escolar? Sim, mas com cuidado. In Revista Educação, a Educação Pré-Escolar, n. ${ }^{\circ} 12,23-32$.

CORREIA, M. (1997). Alunos com Necessidades Educativas Especiais nas Classes Regulares. Porto: Porto Editora.

CORREIA, M. (1999). Alunos com Necessidades Educativas Especiais nas Classes Regulares. Porto: Porto Editora.

CORREIA, M. (2003). Inclusão e Necessidades Educativas Especiais: Um guia para educadores e professores. Porto: Porto Editora.

CORREIA, M. e Serrano, A. (2000). Envolvimento Parental em Intervenção Precoce: Das práticas centradas na criança às práticas centradas na família. Porto: Porto Editora.

COUTINHO, T. (1996). Intervenção Precoce: Dificuldades, necessidades e expectativas das famílias. In Revista Integrar 10, 5-16.

CRUZ, I., Fontes, F., e Carvalho, L. (2003). Avaliação da Satisfação das Famílias Apoiadas pelo PIIP: Resultados da aplicação da escala ESFIP. Lisboa: Secretariado Nacional de Reabilitação.

DGIDC (2008). Educação Especial Manual de Apoio à Prática. Lisboa: Ministério da Educação.

FONSECA, V. (1998). Aprender a Aprender: A educabilidade cognitiva. Lisboa: Editorial Notícias.

FREIXO, M. (2009). Metodologia Científica: Fundamentos e Métodos. Lisboa: Instituto Piaget. 
LEITÃO, F. (2004). A Intervenção Precoce e a Criança com Síndrome de Down: Estudos sobre interacção. Porto: Porto Editora.

MC WILliAM, P., Winton, P. e Crais, E. (2003). Estratégias Práticas para a Intervenção Precoce Centrada na Família. Porto: Porto Editora.

Ministério da Educação. (1997) Orientações Curriculares para a Educação PréEscolar. Lisboa: Departamento da Educação Básica Núcleo de Educação Pré-Escolar.

MIRANDA, M. (2002). A Família como Primeiro Espaço Educativo. In Revista Cadernos de Educação de Infância, 62, 11-15.

MORATO, P. (1995). Deficiência Mental e Aprendizagem. Lisboa: Secretariado Nacional para a Reabilitação das Pessoas com Deficiência.

MORGADO, J. e Beja, A. (2000). As Necessidades das Famílias de Crianças com Necessidades Educativas Especiais. In Revista Inclusão, 1, 45-51.

PEREIRA, F. (1996). As Representações dos Professores de Educação Especial $e$ as Necessidades das Famílias. Lisboa: Secretariado Nacional de Reabilitação.

PEREIRA, F. (1998). As Representações dos Professores de Educação Especial $e$ as Necessidades Educativas Especiais. Lisboa: Secretariado Nacional para a Reabilitação e Integração das Pessoas com Deficiência.

PIMENTEL, J. (1997). Um Bebé Diferente: Da individualidade da intervenção à especificidade de intervenção. Lisboa: Secretariado Nacional de Reabilitação.

PORTUGAL, G. (1992). Ecologia e Desenvolvimento Humano em Bronfenbrenner. Aveiro: Centro de Investigação, Difusão e Intervenção Educacional.

QUIVY, R. (1998). Manual de Investigação em Ciências Sociais. Lisboa: Publicações Gradiva.

RElVAS, P. (1996). O Ciclo Vital da Família: Perspectiva sistémica. Porto: Edições Afrontamento.

RELVAS, P. (2000). O Ciclo Vital da Família. Porto: Edições Afrontamento.

RODRIGUES, D. (2001). Educação e Diferença, Valores e Práticas para uma Educação Inclusiva. Porto: Porto Editora.

RUIVO, B. e Almeida, I. (2002). Contributos para o Estudo das Práticas de Intervenção Precoce em Portugal. Lisboa: Ministério da Educação.

SAMPAIO, D. e Gameiro, J. (1998). Terapia Familiar. Porto: Edições Afrontamento.

SERACENO, C. (1998). Sociologia da Família. Lisboa: Edição Estampa.

SERRANO, A. (2007). Redes Sociais de Apoio e sua Relevância para a Intervenção Precoce. Porto: Porto Editora.

SERRANO, A. e Correia, L. (2005). Parcerias Pais-Professores na Educação da Criança com NEE. In L. Correia Inclusão e Necessidades Educativas 
Especiais: Um guia para educadores e professores (pp. 61-70). Porto: Porto Editora.

SERRANO, A. e Correia, L. (2005a). Inclusão e Intervenção Precoce: para um começo educacional promissor. In L. Correia Inclusão e Necessidades Educativas Especiais: Um guia para educadores e professores (pp. 5359). Porto: Porto Editora.

SOUSA, L. (1998). Crianças (con)fundidas entre a Escola e a Família. Porto: Porto Editora.

TAVARES, J. e Alarcão, I. (1999). Psicologia do Desenvolvimento e da Aprendizagem. Coimbra: Livraria Almedina.

TUCKMAN, B. (1994). Manual de Investigação em Educação. Lisboa: Fundação Calouste Gulbenkian.

Unesco (1994) Declaração de Salamanca. Enquadramento da Acção Necessidades Educativas Especiais: Unesco: ED 94/WS/18.

VEIGA, E. (1995). Intervenção Precoce e Avaliação. Estudo Introdutório. In Revista Labirintos, 1, 29-50.

VIEIRA, R. (1992). Entre a Escola e o Lar: O curriculum e os saberes da infância. Lisboa: Edição Escher.

VIEIRA, F. e Pereira, M. (1996). Se Houvera Quem me Ensinara... A Educação de Pessoas com Deficiência Mental. Coimbra: Fundação Calouste Gulbenkian.

\section{Legislação:}

Decreto-Lei no 281/2009 de 6 de Outubro. Diário da República, $1^{a}$ série - $n^{\circ} 193$, de 6 de Outubro de 2009. Lisboa. Ministério da Educação. 